\title{
EL CAPITAL SOCIAL EN EL PARQUE NACIONAL DE CABAÑEROS
}

\author{
Joaquín Saúl García Marchante \\ Ana Eulalia Aparicio Guerrero \\ Departamento de Geografía y Ordenación del Territorio. Universidad de Castilla-La Mancha \\ Joaquinsaul.Garcia@uclm.es, Ana.Aparicio@uclm.es
}

\section{RESUMEN}

Esta aportación se inscribe en el marco del Proyecto de Investigación «Análisis territorial del capital social en espacios naturales españoles: indicadores de desarrollo socioeconómico (Acrónico: Caso-Natura)», CSO200802919/GEOG, del Ministerio de Ciencia e Innovación. Su objetivo se centra en el análisis del capital social en el Parque Nacional de Cabañeros, de la confianza, el sentido de pertenencia y las redes sociales. Para ello se ha recurrido a la utilización tanto de información cuantitativa, que incluye fuentes bibliográficas y estadísticas, como de información cualitativa obtenida a partir de entrevistas semiestructuradas a informadores cualificados y cuestionarios pasados telefónicamente a una muestra de la población.

Palabras clave: capital social, desarrollo territorial, espacios naturales protegidos.

\section{ABSTRACT}

This contribution registers in the frame of the Project of Investigation «Territorial Analysis of the share capital in natural spanish spaces: indicators of socioeconomic development (Acrónico: Case-Nature)», CSO200802919/GEOG, of the Department of Science and Innovation. Its aim centres on the analysis of the share capital on the National Park of Cabañeros, of the confidence, the sense of belonging and the social networks. For it one has resorted to the utilization so much of bibliographical as statistical and qualitative sources of social

Fecha de recepción: enero 2012.

Fecha de aceptación: marzo 2013. 
analysis, by means of you interview qualified informers and persons in charge of the organizations / institutions linked with the territory.

Key words: share capital, territorial development, natural protected spaces.

\section{CAPITAL SOCIAL Y DESARROLLO RURAL}

El concepto de capital social no es nuevo y en los últimos años asistimos a un auge especial en el uso de este término, especialmente en lo que se refiere a su relación con el desarrollo económico (Wiesinger, 2007). El capital social ha sido incorporado en los análisis de disciplinas como la ciencia política, la economía y más tardíamente la geografía (Radcliffe, 2004), y el número de publicaciones que hacen referencia a este concepto ha ido aumentando de forma considerable en la última década. Sin embargo, las dificultades del capital social por convertirse en un término integrado se ponen de manifiesto en la gran diversidad de definiciones que se vienen dando del mismo.

En cualquier caso, el primer análisis contemporáneo del capital social es realizado por Pierre Bourdieu en los años 80, cuando lo relaciona con otros tipos de capital: «los individuos luchan para conseguir recursos y recompensas, y sus luchas están estructuradas alrededor de su posesión de capital económico, capital social (diferentes clases de relaciones valoradas con otros), capital cultural (primordialmente, conocimiento legítimo) y capital simbólico (prestigio y honor social). (citado en Shucksmith, 2000: 213). En la actualidad, las distintas aproximaciones y enfoques adoptados para analizar el capital social permiten distinguir entre dos grandes tipos de definiciones del concepto: las definiciones estructurales y las definiciones culturales, las primeras se sitúan más en el marco de la sociología, y las segundas estarían dentro del campo de la ciencia política (Herreros y de Francisco, 2001). Por otra parte, el capital social puede ser observado y analizado como fin en sí mismo o como instrumento que permite conseguir un fin, por ejemplo, mayor desarrollo. Sin duda alguna, el interés que suscita actualmente el capital social reside en su potencial contribución a unos mejores resultados de la actividad económica, y por ende de los procesos de desarrollo económico en un territorio. A pesar de los desacuerdos con respecto al término capital social, parece ampliamente aceptada la idea que son determinadas características de las relaciones sociales, de la confianza social, de las instituciones, o de las normas sociales aceptadas por una comunidad las que van a determinar que un territorio consiga unos resultados económicos de desarrollo más o menos satisfactorios.

En el contexto de las zonas rurales desfavorecidas, el potencial de explorar la relación entre capital social y procesos de desarrollo parece aún mayor, porque el capital social pasa a cobrar un valor insospechado ante la deficiencia o inexistencia de otros factores de competitividad territorial (capital económico, infraestructuras de comunicación, capital humano, falta de mano de obra cualificada...). La ventaja competitiva de las zonas rurales está en los recursos que Bryden (1998) denomina «inmóviles»: capital social, capital cultural, capital medioambiental, y conocimiento local.

El capital social en el marco de los territorios y sociedades rurales también adquiere una relevancia especial porque introduce nuevos matices a la consideración del desarrollo, 
que pasa a adoptar un cariz más humanista y no tan economicista. La calidad de vida no se obtiene únicamente a partir de la posesión de bienes cuantificables, sino con la existencia de otros beneficios que se derivan de vínculos sociales estrechos, de relaciones de confianza, o de la existencia de un código de conducta aceptado por la comunidad.

A partir de la década de los ochenta, la teoría del desarrollo endógeno pretende actuar en territorios deprimidos (Stöhr, 1981), descubriendo formas más flexibles en la organización de la producción (Scott, 1998), incorporando las redes en el análisis económico (Johannisson, 1995), comprendiendo que la innovación obedece a un proceso evolutivo (Maillat, 1995) y reconociendo los componentes socioculturales e institucionales (North, 1986). Con el fin de ser más integrador, y siempre con la presencia de una fuerte financiación externa (Buciega, 2004), se prestó atención a la diversificación rural, al enfoque bottom-up, a las iniciativas locales, al apoyo a las empresas autóctonas y a la capacidad de los actores locales, su participación e implicación (Esparcia et al., 2002).

La utilización del concepto en el marco de la iniciativa LEADER se ha vinculado a la capacidad de respuesta del conjunto de la población entendido como un agente diferenciado de cada uno de los individuos que la integra. Para lograr este objetivo se ha tratado de mejorar las habilidades de la comunidad, animar nuevas formas de organización, estimular nuevas vías de vinculación entre grupos e instituciones públicas y ayudar tanto a los individuos como a las organizaciones a lograr una mayor flexibilidad y capacidad de adaptación a situaciones cambiantes. En la práctica esto ha significado apoyar el desarrollo de los individuos y grupos dentro de sus propias comunidades. Esta perspectiva apuesta por reforzar a las comunidades rurales mediante el apoyo a la adquisición de confianza de su propia población, así como del conocimiento y las habilidades de las que disponen, sin olvidar la capacidad para trabajar juntos. En la Unión Europea este tipo de aproximación se ha canalizado de forma relativamente exitosa por parte de la iniciativa comunitaria LEADER, y es importante recordar que la misma se mantiene a instancias de la DG de Agricultura desde 2007 bajo el fondo de desarrollo rural único. En otras palabras, la esencia del programa LEADER podría caracterizarse, en parte, como la creación de varias formas de capital social que podrían beneficiar al conjunto de la comunidad.

Además, en el marco de la AGENDA 2000, el desarrollo tan solo es posible dentro del respeto a la conservación del medio ambiente. Siguiendo a Serrano (2008), la proliferación y localización prioritaria de los espacios naturales protegidos en zonas rurales de montaña y desfavorecidas, plantea inexorablemente la necesidad de coordinar la ordenación del territorio, la planificación ambiental y el desarrollo rural. Según Corraliza (2010), un espacio natural protegido es el «área definida geográficamente que se declara como tal y es regulada y gestionada para lograr objetivos de conservación». No obstante, los espacios naturales protegidos se entienden como instrumentos de revitalización de las economías locales de las zonas rurales marginalizadas convirtiéndose en herramientas básicas para el desarrollo socioeconómico de sus áreas de influencia.

Con la declaración de un espacio natural protegido se establecen una serie de ayudas técnicas, económicas y financieras en las zonas de influencia socioeconómica, por parte principalmente de la administración regional pero también de la nacional y la europea, de acuerdo con las siguientes finalidades: crear infraestructuras y lograr unos niveles de servicios y equipamientos adecuados, mejorar las actividades tradicionales y fomentar otras compatibles con 
el mantenimiento de los valores ambientales, fomentar la integración de los habitantes en las actividades generadas por la protección y gestión del espacio natural, rehabilitar la vivienda rural y conservar el patrimonio arquitectónico, estimular las iniciativas culturales, científicas, pedagógicas y recreativas, compensar suficientemente las limitaciones establecidas y posibilitar el desarrollo socioeconómico de la población afectada ${ }^{1}$.

Como afirman algunos especialistas en materia de protección medioambiental, la salvaguarda especial de un espacio natural puede cumplir con su objetivo si acontecen dos circunstancias que no son contrarias sino complementarias. Por un lado, la población local no ha de mostrarse hostil a medio plazo ante la nueva regulación establecida para ese espacio natural recién protegido. Y, por otro lado, se ha de asegurar el mantenimiento de niveles suficientes de conservación de la flora, la fauna y los hábitats del territorio circundante para evitar, de este modo, que la protección espacial del espacio natural no lo convierta en un enclave ajeno y extraño al entorno biogeográfico y humano que lo rodea. Si estas dos condiciones se dan, el mantenimiento de la biodiversidad podría hacerse compatible con la satisfacción de las necesidades de uso del espacio protegido por la población local. No hay que olvidar, que la percepción generalizada y habitual de los usuarios locales directos de un espacio natural es la de presentarse como principales damnificados en sus expectativas derivadas de la explotación de los recursos naturales del área afectada por la nueva regulación del espacio natural. En definitiva, la conservación, que ha pasado a concebirse como un todo indisociable con el desarrollo socioeconómico sostenible de las poblaciones locales y la protección del entorno sociocultural, no ha de estar reñida con la valorización y la ordenación de recursos como el paisaje, el patrimonio histórico y cultural y la gastronomía, con el fin de impulsar y diversificar las microeconomías locales (Serrano, 2008).

\section{OBJETIVOS Y METODOLOGÍA}

En relación con todo lo apuntado hasta ahora, esta comunicación tiene como objetivos analizar la confianza social en el Parque Nacional de Cabañeros (Ciudad Real), para conocer los contextos de confianza entre los agentes e instituciones, así como detectar el nivel de identidad territorial que tiene la población respecto a su municipio, espacio natural y escalas supralocales y el modo en que todo ello ha influido en el desarrollo territorial del Parque. Asimismo, pretende evaluar las redes sociales en el espacio seleccionado identificando las relaciones e interacciones sociales entre los distintos actores locales y comprobando la existencia de redes formales a través del tejido asociativo, como máxima expresión de las redes sociales.

Para conseguir que exista homogeneidad entre todos los estudios de caso del proyecto de investigación en el que se inserta este artículo, las áreas de influencia socioeconómicas analizadas deben representar el $85 \%$ de sus correspondientes espacios naturales. Para ello hemos ido seleccionado municipios hasta alcanzar dicha cifra teniendo en cuenta los siguientes criterios: incluir los municipios que tengan el $100 \%$ de su superficie en el Espacio Natural Protegido (ENP), en caso de no alcanzar el mínimo establecido, incorporar a los municipios

1 Junta de Castilla y León. Disponible en http://www.jcyl.es/web/jcyl/MedioAmbiente/es/Planti1la100/1131977535996 
que tengan más del $10 \%$ de su superficie dentro del ENP, y en caso que aún no se cubra, añadir aquellos municipios que tengan entre un 10-5 \% de su superficie dentro del ENP.

En el caso de Castilla-La Mancha, y más en concreto del Parque Nacional de Cabañeros, se han seleccionado 4 municipios situados en la provincia de Ciudad Real (Alcoba de los Montes, Horcajo de los Montes, Navas de Estena y Retuerta del Bullaque), y 2 en la de Toledo (Hontanar y Los Navalucillos), con una población total de 6.115 habitantes. En la actualidad, algo más del $55 \%$ del parque es de titularidad pública, el resto es de titularidad privada.

Para poder conocer en qué medida el capital social juega un papel importante en los procesos de desarrollo de esta zona debemos ser capaces de establecer instrumentos que nos permitan su correcta medición. Son diversos los autores que desde distintas disciplinas y aproximaciones metodológicas han establecido indicadores para medir cada una de las dimensiones del capital social. Posiblemente ha sido la amplitud de conceptos que se incluyen bajo la definición de capital social, y su clara referencia a relaciones y procesos sociales lo que ha podido propiciar un mayor uso de técnicas de análisis cualitativas frente a las cuantitativas. Son más frecuentes los estudios que se basan en el análisis de datos obtenidos a partir de entrevistas en profundidad, que los que incluyen análisis econométricos más complejos o análisis de redes. En este sentido, y por lo que respecta a la organización y metodología utilizada en nuestra investigación, aparte de la sistematización de la información cuantitativa disponible, que incluye fuentes bibliográficas y estadísticas, se ha trabajado principalmente con metodologías y técnicas de investigación social y técnicas cualitativas de análisis socioterritorial.

En cuanto a la selección de la muestra de análisis, el estudio de las organizaciones en nuestro caso se centra en los colectivos sociales (asociaciones civiles) e instituciones (órganos colegiados en el ENP). Para ello seleccionamos una Muestra Aleatoria Simple Estratificada (MASE) de todas las asociaciones que hay en cada ENP, en nuestro caso de Cabañeros, con un nivel de confianza de $95 \%$ y un error muestral del $5 \%$.

La herramienta metodológica propuesta para la recopilación de información ha sido el empleo de la encuesta y entrevista. La encuesta incluye distintos tipos de preguntas dirigidas a conocer los tipos y niveles de confianza, sentido de pertenencia y participación social propuestas en el marco conceptual-analítico, y está construida por preguntas cerradas para facilitar el análisis y comparación entre los ENP y sus territorios. Se trata de un conjunto de ítems presentados en forma de afirmaciones o juicios ante los cuales se pide al sujeto que muestre su reacción eligiendo uno de los cuatro puntos de una escala. Está compuesta por 13 preguntas con 92 ítems en la escala Likert, siendo construida principalmente por variables cualitativas ordinales politómicas que en este estudio son preguntas cerradas en cuatro niveles (1-2-3-4) (Hernández et al, 2003; López y Juarez, 2004; Chimi y Rusell, 2009). Aunque este método se remonta a principios de los años 30, hoy en día sigue siendo uno de los más populares y vigentes. Además de este tipo de cuestiones, se incluyen una pregunta abierta (pregunta 7) para verificar los elementos más representativos de los ENP y otra dicotómica (pregunta 11).

En definitiva, un total de 25 encuestas estandarizadas que se complementaron con dos entrevistas semiestructuradas a informadores cualificados -en este último caso el directorconservador del Parque y el gerente del Grupo de Acción Local a quienes sus responsabili- 
dades y/o cargos les proporcionan una visión de conjunto enriquecida en muchas ocasiones con la capacidad de análisis diacrónico-, y cuestionarios pasados telefónicamente a una muestra de la población, organizaciones/instituciones vinculadas al territorio -miembros de los órganos colegiados y todas aquellas asociaciones radicadas en los municipios del Área de Influencia Socioeconómica (AIS) del parque que aceptaron colaborar en la investigación-, en los que se intentó obtener información sobre niveles de confianza, redes sociales y normas y pautas de comportamiento comunitario.

\section{CABAÑEROS: PARQUE NATURAL Y PARQUE NACIONAL}

El Parque Nacional de Cabañeros se encuentra localizado entre el cuadrante noroccidental de la provincia de Ciudad Real y el suroccidental de Toledo. Incluido en el sistema orográfico de los Montes de Toledo, lo limitan al este y oeste los ríos Bullaque y Estena, respectivamente, y abarca la mitad meridional del Macizo de Chorito, la parte superior de la rampa pedregosa conocida como «raña» de Santiago, y el Macizo de Rocigalgo, cota más elevada de los Montes de Toledo.

Está formado por un conjunto de sierras paleozoicas alternando con superficies de raña plio-cuaternarias (extensas llanuras originadas por relleno con materiales erosionados de las sierras circundantes), abarcando un total de 40.000 hectáreas. En Cabañeros se presentan todos los elementos propios de los relieves montañosos denominados apalachenses. En estos relieves no existen desniveles ni elevaciones considerables y, sin embargo, el terreno resulta accidentado y los macizos se adaptan a la dirección de los pliegues.

Desde el siglo XIII al XIX fue propiedad del ayuntamiento de Toledo. La transformación radical de la titularidad de la tierra en Cabañeros, vino con la desamortización de Madoz en 1885. El mantenimiento de unas estrictas Ordenanzas de Uso y los escasísimos niveles de rendimiento económico que se demandó de esta zona son los factores que han permitido el actual estado de conservación del medio natural del Parque.

En 1982 Cabañeros empieza a conocerse en todo el país debido a la intención de convertirlo en campo de tiro. Afortunadamente, la Junta de Comunidades de Castilla-La Mancha lo declara Parque Natural mediante el Decreto 95/1988. La protección del espacio se vio aún más reforzada cuando unos años después, en 1995, consiguió obtener la máxima protección nacional: Parque Nacional (figuras 1 y 2).

La extracción de carbón vegetal, el pastoreo y la agricultura de subsistencia fueron las principales actividades que se desarrollaron en el entorno de Cabañeros en el pasado. De hecho, el Parque Nacional de Cabañeros debe su nombre a las chozas utilizadas tradicionalmente por pastores y carboneros como refugio temporal de sus labores en el campo. En la actualidad, la ganadería sigue siendo una actividad habitual en los alrededores del parque, con una producción de queso de excelente calidad. Además, se sigue cultivando cereal y olivar de la variedad cornicabra, también llamada cornezuelo, origen del aceite de la Denominación de Origen «Aceites de los Montes de Toledo». Las tradicionales actividades de explotación de los recursos naturales de Cabañeros, como en el resto de parques nacionales, están permitidas siempre que se garantice un aprovechamiento sostenido de las especies y los ecosistemas. Asimismo, otro de los aprovechamientos tradicionales en el entorno del parque son los recursos cinegéticos de las grandes fincas existentes en las inmediaciones. 


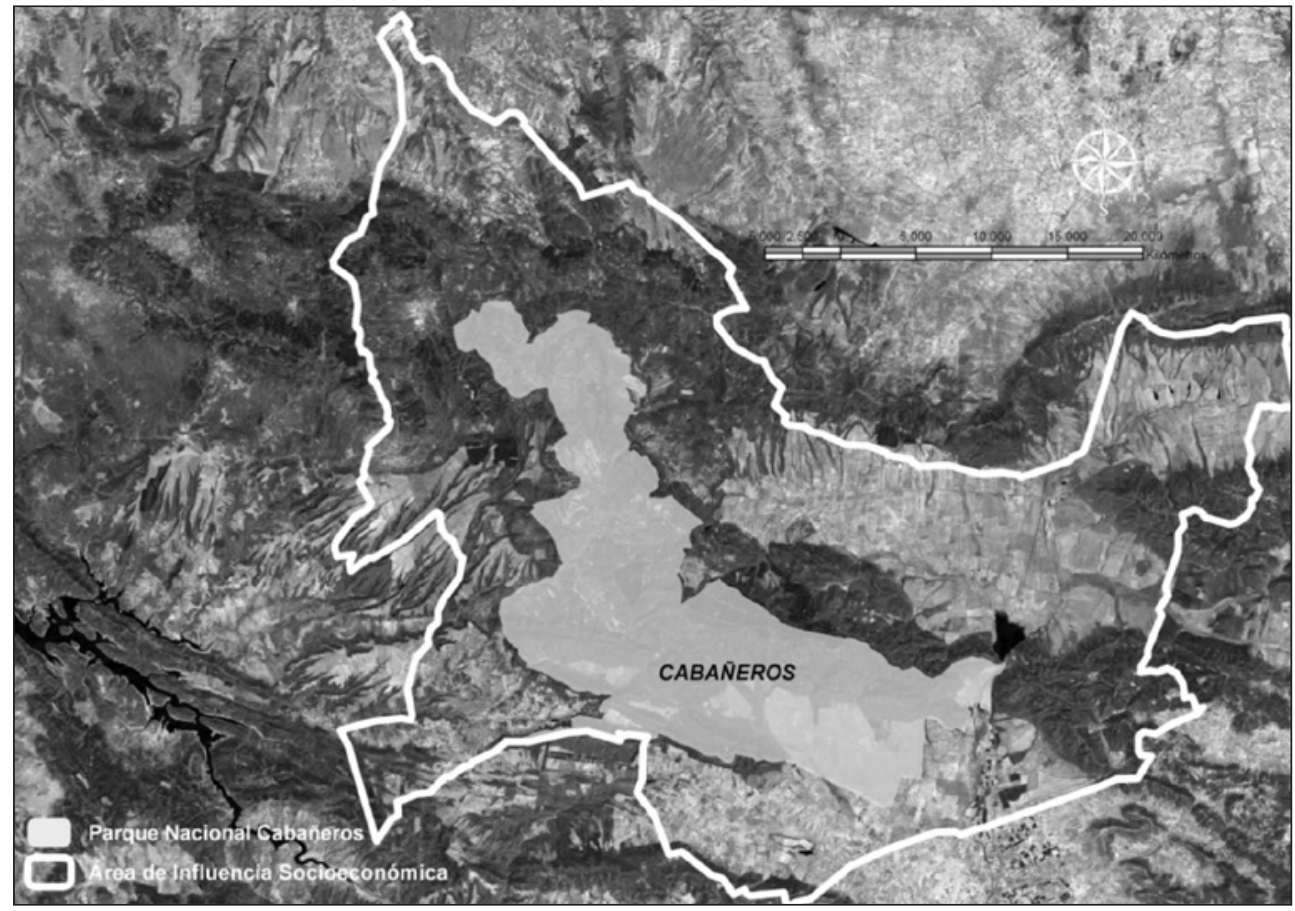

Fuente de la imagen: http://image2000.jrc.ec.europa.eu/. Elaboración propia.

Por lo que respecta al turismo de la zona, se percibe un aumento considerable en la evolución de las visitas al ENP a partir del momento en que se declara Parque Nacional, fecha en la que se superan los 15.000 visitantes al año y punto de partida de la línea ascendente de visitantes sostenida a lo largo de los años. En 1998, el Parque contaba con más de 50.000 visitas al año y en 2004 ya se habían superado las 70.000 visitas anuales. Esto indica, pues, que progresivamente la tendencia generalizada de Cabañeros ha sido ir creciendo en visitas a pesar de las limitaciones y restricciones que el ENP sufre a la hora de canalizar los flujos (se trata del parque nacional con la relación más baja de visitantes por hectárea y año de toda la red española), uno de los principales motivos de conflicto entre la dirección del parque y los agentes implicados (alojamientos, empresarios turísticos, etc.). No obstante, las relaciones entre la actual administración del parque y el Grupo de Acción Local han mejorado mucho, y se ha conseguido que en agosto de 2009 el Parque Nacional de Cabañeros recibiera de manera oficial el certificado de adhesión a la Carta Europea de Turismo que otorga la Federación EUROPARC.

Hasta 1994, año en el que se crea la Mancomunidad de Cabañeros, las actuaciones a favor del desarrollo en estos municipios partían de la administración regional o local. No existía una estructura comarcal que tuviese una estrategia mínimamente diseñada. Las nuevas circunstancias de la comarca (la creación de un Parque Nacional) y sus valiosos recursos 


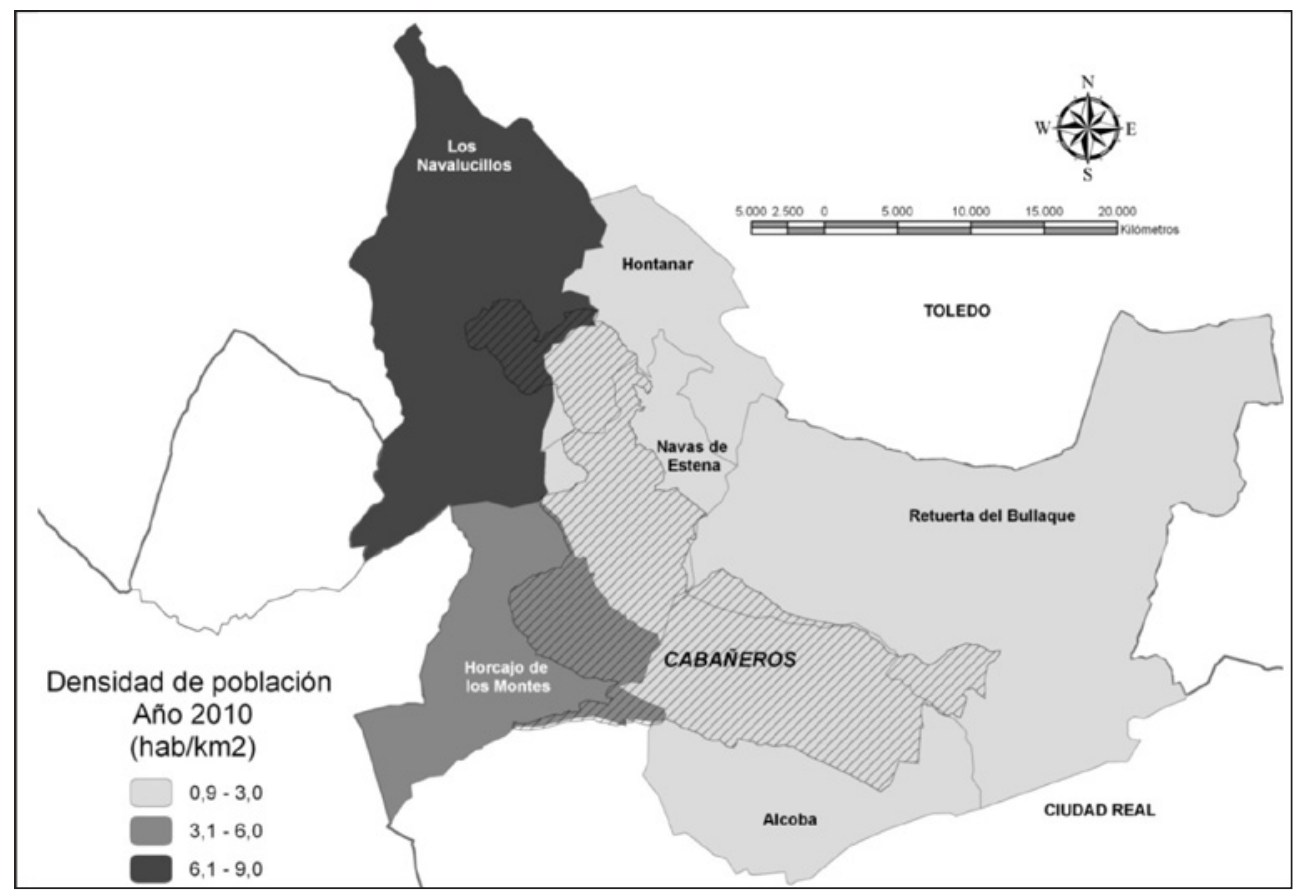

Fuente de la imagen: http://image2000.jrc.ec.europa.eu/ Elaboración propia.

permitieron orientar la iniciativa LEADER hacia la elaboración de una estrategia ligada al nombre de Cabañeros, estrategia que se pretendió continuara con la Asociación Concejo Mancomunidad de Cabañeros, constituida el 5 de febrero de 1997, y con la aplicación de la agenda 21 Local, que pretende lograr el más adecuado desarrollo sostenible de los municipios mancomunados, el bienestar de sus habitantes y la mejora y conservación del entorno natural y cultural.

En el momento actual, resulta paradójico que un parque nacional como Cabañeros (en la red de «élite» de los ENP españoles) carezca de las herramientas básicas de gestión por encontrarse desfasadas, anuladas o bien pendientes de una aprobación definitiva. Por un lado el Plan de Ordenación de los Recursos Naturales (PORN), anulado por sentencia del Tribunal Supremo en 2003 y, por otro, el Plan Rector de Uso y Gestión (PRUG) en tramitación desde hace casi una década y todavía pendiente de aprobación definitiva. En cualquier caso, la declaración ha tenido sin duda aspectos positivos, aunque también sus sombras. Entre los primeros, el «descubrimiento social» de esta comarca que había salido a la palestra como posible centro de operaciones de la OTAN para conseguir adquirir una identidad propia. A los beneficios para el territorio se suman las iniciativas procedentes de fondos europeos, 


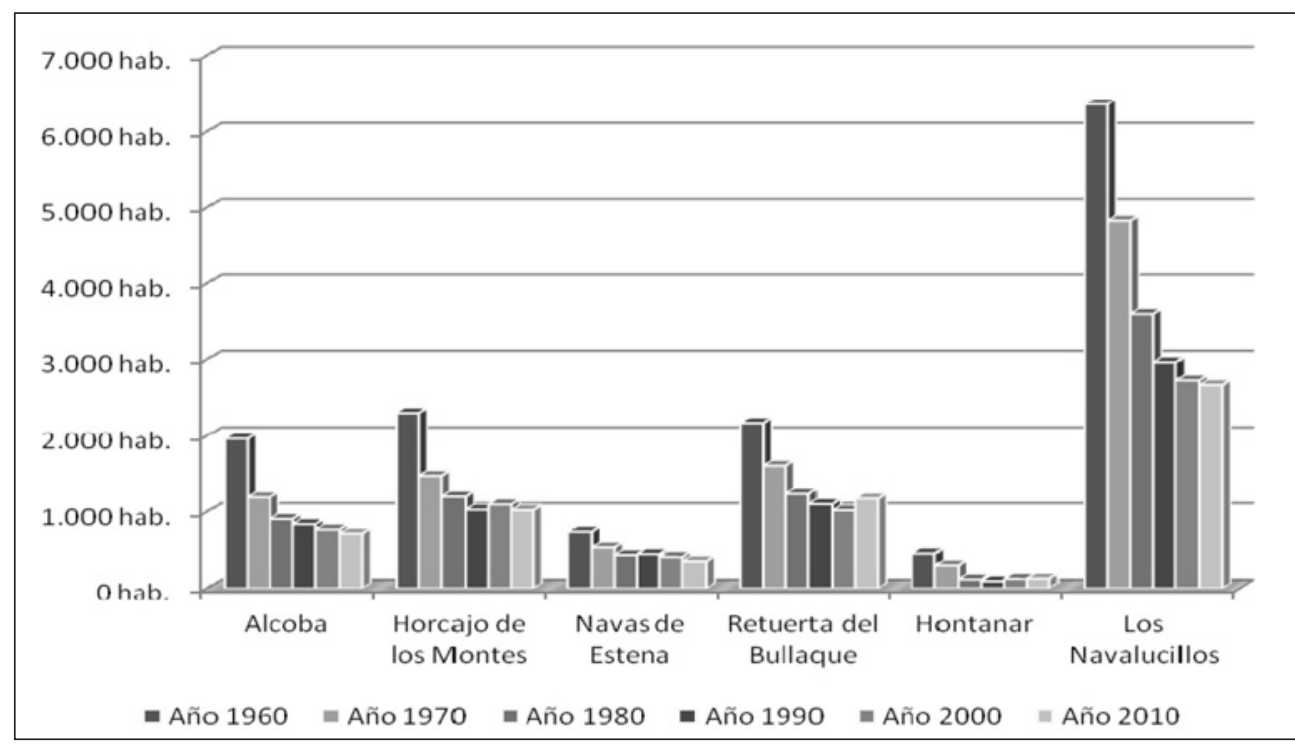

Fuente: INE. Elaboración propia.

que están favoreciendo un cambio económico progresivo hacia una cierta terciarización con predominio de las actividades vinculadas al turismo (rural, verde, etc.) y al medio ambiente. Todo ello ha supuesto, junto con las subvenciones procedentes de Parques Nacionales, una mejora importante en la calidad de vida de la población local (mejoras en viviendas, infraestructuras, caminos, servicios, etc.). Ahora bien, ello no ha podido detener la sangría demográfica que acusan todos los municipios del Área de Influencia Socioeconómica (AIS) (figura 3 ), que han venido perdiendo población de manera constante con el consiguiente envejecimiento de la población y la falta de recambio generacional por las bajas tasas de natalidad, proceso relacionado con una situación estructural en la que se ven envueltos aspectos como la carencia de servicios sanitarios especializados y sobre todo la falta de expectativas laborales para los más jóvenes.

\section{ANÁLISIS DEL CAPITAL SOCIAL A PARTIR DE LOS CUESTIONARIOS ESTANDARIZADOS}

Partiendo de la hipótesis de que la confianza, la reciprocidad y la solidaridad son elementos básicos del capital social, hemos tratado de medirlas con el fin de valorar su papel en el apoyo de la cooperación y los mecanismos de intercambio. Cabañeros es el espacio de montaña más despoblado de la provincia de Ciudad Real, territorio envejecido y desfavorecido a pesar de que los programas europeos y españoles de desarrollo regional se han venido implementando desde 1991. 


\subsection{La confianza}

De la aplicación del cuestionario a representantes de asociaciones incursas en el territorio implicado, se ha obtenido una interesante información relacionada con las características sociológicas de sus habitantes. La totalidad de la población demuestra ser altamente solidaria, interesada, independiente, cívica y participativa respecto a temas relacionados con la «importancia que tiene para ellos ayudar a personas que están en peor situación que la suya», «participar en asociaciones voluntarias», «formarse una opinión propia, independientemente de la de los demás», «obedecer siempre las leyes y las normas» $\mathrm{y}$ «votar en las decisiones» (cuadro 1).

Mientras la ayuda y solidaridad con aquellos que están en peor situación que uno concita la máxima adhesión, el menor entusiasmo a la hora de «valorar la importancia de respetar leyes y normas» y «votar en las decisiones», podría estar justificado por el hecho de ser un espacio tradicionalmente vinculado a la gran propiedad y a la presencia de una economía marginal tradicional, espacio que puede haber asumido valores de «outsider» o fuera de la ley por entender que el status quo y el marco normativo son ajenos a sus intereses y necesidades.

Cuadro 1

¿QUÉ IMPORTANCIA TIENE PARA USTED CADA UNO DE LOS SIGUIENTES COMPORTAMIENTOS?

\begin{tabular}{|l|l|l|}
\hline & \multicolumn{2}{|c|}{$\%$} \\
\hline $\begin{array}{l}\text { Ayudar a personas que están en peor situación que } \\
\text { uno }\end{array}$ & $\begin{array}{l}\text { Insolidario } \\
\mathbf{0}\end{array}$ & $\begin{array}{l}\text { Solidario } \\
\mathbf{1 0 0}\end{array}$ \\
\hline Participar activamente en política & $\begin{array}{l}\text { Indiferente } \\
\mathbf{7 7 , 8}\end{array}$ & $\begin{array}{l}\text { Militante } \\
\mathbf{2 2 , 2}\end{array}$ \\
\hline Participar en asociaciones voluntarias & $\begin{array}{l}\text { Desinteresado } \\
\text { 0 }\end{array}$ & $\begin{array}{l}\text { Interesado } \\
\mathbf{1 0 0}\end{array}$ \\
\hline $\begin{array}{l}\text { Formarse una opinión propia, independientemente } \\
\text { de la de los demás. }\end{array}$ & $\begin{array}{l}\text { Influenciable } \\
\mathbf{0}\end{array}$ & $\begin{array}{l}\text { Independiente } \\
\mathbf{1 0 0}\end{array}$ \\
\hline Obedecer siempre las leyes y las normas & $\begin{array}{l}\text { Incívico } \\
\mathbf{0}\end{array}$ & $\begin{array}{l}\text { Cívico } \\
\mathbf{1 0 0}\end{array}$ \\
\hline Votar en las decisiones & Absentista & $\begin{array}{l}\text { Participativo } \\
\mathbf{5 5 , 6}\end{array}$ \\
\hline
\end{tabular}

Fuente: Elaboración propia.

\subsubsection{La confianza estratégica}

Algunos especialistas subrayan que las regiones montañosas, comparadas con otros tipos de espacios rurales, todavía se caracterizan por un sistema de fuertes relaciones comunitarias (Magnani y Struffi, 2009), mientras otros afirman que las comunidades de montaña son a menudo «sociedades divididas» (Osti, 2000), donde los acelerados cambios provocados por 
la modernización han venido a sumar viejas rivalidades entre familias con nuevos conflictos entre categorías profesionales (agricultores, ganaderos, empresarios turísticos) que persiguen objetivos económicos diferentes cuando no enfrentados.

Si nos detenemos en las preguntas que aluden a los aspectos de interés personal, en el marco de la confianza estratégica, se intenta ver qué opina la población sobre si «es muy difícil que una persona pueda hacer algo por el medio ambiente», «si sus acciones pueden realmente influir en el medio ambiente», «si confía en el funcionamiento de las empresas de su territorio» $\mathrm{y}$ «en el futuro del mismo» (cuadro 2). En cuanto a la confianza en el futuro de su comarca, se muestran optimistas $(77,8 \%)$ y esta confianza se debe quizá a la consideración de que el futuro está en sus manos en tanto en cuanto la totalidad de la población encuestada piensa que «sus acciones pueden realmente influir en el medioambiente» y el 88,9\% que «pueden hacer algo por el medio ambiente». Por lo que respecta a las empresas de su territorio, las consideran viables en un elevado porcentaje $(77,8)$.

Cuadro 2

ESTÁ DE ACUERDO CON LAS SIGUIENTES AFIRMACIONES:

\begin{tabular}{|l|c|c|}
\hline $\begin{array}{l}\text { Es muy difícil que una persona como yo pueda hacer } \\
\text { algo por el medio ambiente. }\end{array}$ & $\begin{array}{c}\text { Pasivo } \\
\mathbf{1 1 , 1}\end{array}$ & $\begin{array}{c}\text { Activo } \\
\mathbf{8 8 , 9}\end{array}$ \\
\hline $\begin{array}{l}\text { Mis acciones pueden realmente influir en el medio } \\
\text { ambiente }\end{array}$ & $\begin{array}{c}\text { Indeciso } \\
\mathbf{0}\end{array}$ & $\begin{array}{c}\text { Decidido } \\
\mathbf{1 0 0}\end{array}$ \\
\hline $\begin{array}{l}\text { Confío en el funcionamiento de las empresas de mi } \\
\text { territorio }\end{array}$ & Inviable & Viable \\
\hline Confío en el futuro de mi territorio & $\mathbf{2 2 , 2}$ & $\mathbf{7 7 , 8}$ \\
\hline
\end{tabular}

Fuente: Elaboración propia.

\subsubsection{La confianza normativa}

Las respuestas recogidas acerca de cuestiones que tienen que ver con la confianza normativa y los comportamientos individuales de los encuestados respecto a sus valores éticos como ciudadano, sus derechos y obligaciones ciudadanas, ya sea en relación con sus deberes para con la hacienda pública o como con su proceder ante situaciones incomodas que miden la conducta humana presentan a una población fundamentalmente íntegra y educada.

Así, ante «la posibilidad de acceder al disfrute de fondos públicos sin tener derecho a ello», las respuestas alcanzan valores altos de integridad (89\%). Ante la situación de «poder defraudar a la hacienda pública», la respuesta de un $66,7 \%$ de defraudadores no debe entenderse en el sentido de la existencia de ese contingente con ánimo defraudador, sino en la poca confianza que estos tienen sobre la exigencia universal en el fenómeno recaudatorio. Si relacionamos el dinero con la fortuna de «encontrarlo perdido en la calle y proceder a su devolución», las respuestas muestran el peso del anonimato y aquí los valores éticos se derrumban en beneficio de la ocultación que posiblemente no sea realmente una actuación deshonesta si 
el hallazgo no alcanza altos valores crematísticos o no existen elementos identificadores de su anterior propietario, por tanto, descienden los valores de honestidad, alcanzando el 44,4\%.

En la coyuntura, por otro lado muy posible, de «dañar a otro vehículo que se encuentra aparcado», destaca un elevado grado de educación cívica, el 88,9\%. Este nivel de respuesta identifica a ciudadanos educados, usuarios todos de automóviles y conscientes del trastorno que se ocasiona al perjudicado, sabiendo que existe por medio un seguro que dispensa al causante de cualquier desembolso.

La confianza en colectivos y en instituciones deja una imagen diáfana de la incondicionalidad de los individuos respecto a ciertas instituciones muy consolidadas en la sociedad, como «la familia» o la policía, las instituciones más valoradas por la totalidad de los encuestados (cuadro 3). Ahora bien, cuando se trata de otras instituciones que forman el elenco administrativo del ámbito territorial, hasta incluso la Unión Europea, se detecta cierta desconfianza que apunta una orla de descrédito en orden centrífugo, es decir, el ayuntamiento, la mancomunidad, la diputación provincial y el gobierno regional, sugieren confianzas distintas y curiosas. A la familia y policía le siguen los «vecinos del mismo pueblo», «los de otros municipios de la comarca», «la diputación» y «el equipo técnico del ENP», todos con el $88,9 \%$ de población sociable, solidaria y crédula, seguida por «el equipo técnico del LEADER-PRODER» $(77,8 \%)$ y «el propio ayuntamiento» (66,7). Resulta curioso, aunque podría reforzar la hipótesis antes esbozada, la falta de confianza de las asociaciones de Cabañeros en instituciones como «la mancomunidad» $(55,6 \%)$, y, sobre todo «el gobierno regional» $(77,8 \%)$, por no hablar «del sistema judicial» $(88,9 \%)$, de las que parecen sentirse más alejados. Por el contrario la confianza en el equipo técnico del parque nacional así como la confianza en el futuro de la zona son significativamente altos $(88,9 \%)$. En relación con esto hay que tener en cuenta que la implementación de políticas de desarrollo socioeconómico para los municipios del área de influencia socioeconómica del parque nacional han comenzado a dejar ver sus resultados, con financiaciones que proceden tanto del organismo autónomo de parques nacionales, como de fondos europeos vinculados a las políticas de desarrollo regional, especialmente en materia de infraestructuras y equipamientos turísticos, cuyo desarrollo ha sido más que notable. En este sentido, «la Unión Europea» queda bien considerada con niveles de confianza altos, donde quizá haya pesado el conocimiento de que los programas de desarrollo aplicados en la zona, llevan la financiación con fondos europeos.

En todo espacio natural protegido es necesario organizar «la participación de la población local» como parte sustancial de las tareas de planificación del desarrollo sostenible, pudiendo ayudar a generar un consenso en torno a la gestión de los espacios protegidos. La participación desarrolla el sentido de pertenencia y la identificación de las personas con su medio, proporciona oportunidades para el aprendizaje y para ejercer la responsabilidad ambiental, facilita que los intereses de la gente sean tenidos en cuenta corrigiendo tendencias tecnocráticas, y puede prevenir conflictos. Según Garayo (2001), la intervención y participación activas de la población rural en la gestión de los espacios naturales protegidos, se configura en un elemento decisivo en la integración en unas políticas territoriales globales que abarquen la conservación y el uso racional del territorio (Fernández, 1975; Valenzuela, 1989; Castroviejo, 1993; Garayo, 1998).

La información proporcionada por la población entrevistada parece reflejar, ante todo, la opinión general sobre el papel de los gestores y entes administrativos relacionados con la 
Cuadro 3

CUÁNTO CONFÍA USTED PERSONALMENTE EN CADA UNO DE LOS SIGUIENTES COLECTIVOS/PERSONAS/ SITUACIONES:

\begin{tabular}{|c|c|c|}
\hline & \multicolumn{2}{|c|}{$\%$} \\
\hline Familia & $\begin{array}{l}\text { Insolidario } \\
\mathbf{0}\end{array}$ & $\begin{array}{l}\text { Respaldado } \\
\mathbf{1 0 0}\end{array}$ \\
\hline Vecinos del mismo pueblo & $\begin{array}{l}\text { Huraño } \\
\mathbf{1 1 , 1}\end{array}$ & $\begin{array}{l}\text { Sociable } \\
\mathbf{8 8 , 9}\end{array}$ \\
\hline Vecinos de otros municipios de la comarca & $\begin{array}{l}\text { Insolidario } \\
\mathbf{1 1 , 1}\end{array}$ & $\begin{array}{l}\text { Solidario } \\
\mathbf{8 8 , 9}\end{array}$ \\
\hline En el ayuntamiento & $\begin{array}{l}\text { Descreído } \\
\mathbf{3 3 , 3}\end{array}$ & $\begin{array}{l}\text { Confiado } \\
\mathbf{6 6 , 7}\end{array}$ \\
\hline En la mancomunidad & $\begin{array}{l}\text { Descreído } \\
\mathbf{5 5 , 6}\end{array}$ & $\begin{array}{l}\text { Confiado } \\
\mathbf{4 4 , 4}\end{array}$ \\
\hline Gobierno Regional & $\begin{array}{l}\text { Reticente } \\
\mathbf{7 7 , 8}\end{array}$ & $\begin{array}{l}\text { Confiado } \\
\mathbf{2 2 , 2}\end{array}$ \\
\hline En la Diputación & $\begin{array}{l}\text { Incrédulo } \\
11,1\end{array}$ & $\begin{array}{l}\text { Crédulo } \\
\mathbf{8 8 , 9}\end{array}$ \\
\hline En la UE & $\begin{array}{l}\text { Incrédulo } \\
\mathbf{1 8 , 8}\end{array}$ & $\begin{array}{l}\text { Crédulo } \\
\mathbf{8 1 , 3}\end{array}$ \\
\hline En el equipo técnico del ENP & $\begin{array}{l}\text { Incrédulo } \\
\mathbf{1 1 , 1}\end{array}$ & $\begin{array}{l}\text { Crédulo } \\
\mathbf{8 8 , 9}\end{array}$ \\
\hline En el equipo técnico de LEADER-PRODER & $\begin{array}{l}\text { Reticente } \\
\mathbf{2 2 , 2}\end{array}$ & $\begin{array}{l}\text { Confiado } \\
\mathbf{7 7 , 8}\end{array}$ \\
\hline En la policía & $\begin{array}{l}\text { Desconfiado } \\
\mathbf{0}\end{array}$ & $\begin{array}{l}\text { Confiado } \\
\mathbf{1 0 0}\end{array}$ \\
\hline En el sistema judicial & $\begin{array}{l}\text { Reticente } \\
\mathbf{8 8 , 9}\end{array}$ & $\begin{array}{l}\text { Confiado } \\
\mathbf{1 1 , 1}\end{array}$ \\
\hline En el futuro para la zona & $\begin{array}{l}\text { Desesperanzado } \\
\mathbf{1 1 , 1}\end{array}$ & $\begin{array}{l}\text { Esperanzado } \\
\mathbf{8 8 , 9}\end{array}$ \\
\hline
\end{tabular}

Fuente: Elaboración propia.

dinámica de los parques naturales y el juicio de los entrevistados sobre el funcionamiento de algunos de los aspectos específicos de la gestión de los mismos².

En primer lugar, conviene decir que se registra una tendencia a una evaluación positiva de los distintos aspectos de la gestión considerados en este estudio: «la información que les

2 CORRALIZA, J. A.; MARTÍN, R.; BERENGUER, J.; MORENO, M. (2002): Los espacios naturales protegidos, escenarios de intervención psicosocial Intervención Psicosocial, vol. 11, núm. 3, 2002, pp. 303-316. Colegio Oficial de Psicólogos. Madrid, España. 
interesa llega a tiempo» $(88,9 \%)$; en general, «la valoración sobre las posibilidades de participación», y «las oportunidades para discutir con los gestores los asuntos del espacio natural protegido» son valoradas también positivamente por la mayoría de los entrevistados $(66,7 \%)$; «saben dónde y a quién dirigirse para resolver problemas relacionados con la gestión del parque que les afectan», $(77,8 \%)$; y «existen medios a su alcance para consultar o reclamar si es necesario a los gestores del espacio» $(77,8 \%$ ) (cuadro 4). En cuanto a la información sobre los instrumentos ambientales, la valoración y el grado de acuerdo respecto a «las posibilidades de participación y gestión por parte de la población local» es relativamente elevada, tanto entre los miembros del órgano colegiado como entre las asociaciones entrevistadas. Así, ante la afirmación «los gestores y los representantes del espacio natural tienen en cuenta la opinión de la gente del municipio» es contundente la distribución de frecuencias resultantes, con un 55,6\% que piensa que los actuales gestores son dialogantes. Por último, el $89 \%$ de la población se siente «interesada por saber algo más sobre el funcionamiento del mismo». En definitiva, hay un elevado porcentaje de población que opina que los órganos de gestión del parque son eficientes, accesibles y operativos, con elevadas tasas de satisfacción.

\section{Cuadro 4}

DIGA SI LA POBLACIÓN DEL ESPACIO NATURAL PROTEGIDO QUE REPRESENTA, SE SIENTE IDENTIFICADA CON LAS SIGUIENTES AFIRMACIONES EN RELACIÓN CON LOS ÓRGANOS DE GESTIÓN DEL ESPACIO NATURAL

\begin{tabular}{|l|l|l|}
\hline & \multicolumn{2}{|c|}{$\%$} \\
\hline $\begin{array}{l}\text { La información que nos interesa nos llega claramente a } \\
\text { tiempo }\end{array}$ & $\begin{array}{l}\text { Ineficiente } \\
\mathbf{1 1 , 1}\end{array}$ & $\begin{array}{l}\text { Eficiente } \\
\mathbf{8 8 , 9}\end{array}$ \\
\hline $\begin{array}{l}\text { Existen oportunidades para discutir con los gestores los } \\
\text { asuntos del ENP }\end{array}$ & $\begin{array}{l}\text { Lejano } \\
\mathbf{3 3 , 3}\end{array}$ & $\begin{array}{l}\text { Próximo } \\
\mathbf{6 6 , 7}\end{array}$ \\
\hline $\begin{array}{l}\text { Sé a quién y donde dirigirme para resolver problemas } \\
\text { relacionados con la gestión del parque que me afectan }\end{array}$ & $\begin{array}{l}\text { Inaccesibles } \\
\mathbf{2 2 , 2}\end{array}$ & $\begin{array}{l}\text { Accesibles } \\
\mathbf{7 7 , 8}\end{array}$ \\
\hline $\begin{array}{l}\text { Los actuales gestores y los representantes tienen en } \\
\text { cuenta la opinión de la gente del municipio }\end{array}$ & $\begin{array}{l}\text { Autoritario } \\
\mathbf{4 4 , 4}\end{array}$ & $\begin{array}{l}\text { Dialogante } \\
\mathbf{5 5 , 6}\end{array}$ \\
\hline $\begin{array}{l}\text { Existen medios al alcance de la población para consultar } \\
\text { o reclamar si es necesario a los gestores del espacio }\end{array}$ & $\begin{array}{l}\text { Inoperativo } \\
\mathbf{2 2 , 2}\end{array}$ & $\begin{array}{l}\text { Operativo } \\
\mathbf{7 7 , 8}\end{array}$ \\
\hline $\begin{array}{l}\text { Me siento interesado por saber algo más sobre el } \\
\text { funcionamiento del mismo }\end{array}$ & $\begin{array}{l}\text { Desinteresado } \\
\mathbf{1 1 , 1}\end{array}$ & $\begin{array}{l}\text { Interesado } \\
\mathbf{8 8 , 9}\end{array}$ \\
\hline
\end{tabular}

Fuente: Elaboración propia.

\subsubsection{La confianza cognitiva}

En materia de gobernanza ambiental, y en relación con la confianza cognitiva, cuando se les interroga acerca de su grado de satisfacción sobre aspectos que van de lo estrictamente personal al entorno local o regional, sin olvidar el funcionamiento de la democracia, las respuestas se focalizan en los extremos de tal modo que existe unanimidad casi total en 
ellas, con sólo dos excepciones, «su vida últimamente», con la que sorprendentemente, y en relación al conformismo de los habitantes serranos, casi todos parecen estar satisfechos detectándose alguna muestra de inconformismo, lógica por otro lado, cuando se trata de las aspiraciones personales o de objetivos no alcanzados, próximos, tal vez, al fracaso personal, y «la situación económica de la región» que suscita el mayor descontento ya que la totalidad de la población encuestada se manifiesta resignada ante esta situación, declarando abiertamente sentirse muy insatisfechos, algo que, por otra parte, resulta lógico en medio de la actual crisis económica (cuadro 5). También tenemos que tener en cuenta que hablamos de un territorio desfavorecido de montaña, afirmación que se complementa con una visión negativa de la labor del gobierno regional.

Por su parte, «la labor que realiza el órgano colegiado del parque nacional» resulta muy valorada por todos los entrevistados, tanto por los miembros del propio patronato como por las asociaciones, manifestando un grado máximo de satisfacción. Respecto a esta benevolente valoración de los órganos colegiados habría que recordar que su configuración refleja el peso e influencia del propio gobierno regional, pues además de la dirección-conservación del parque y la propia presidencia del órgano colegiado, cargos de confianza designados por la administración, tienen voz y voto los representantes de diversas consejerías con intereses y competencias dentro del territorio protegido.

«La labor de los ayuntamientos» de la zona, a pesar de su histórica presencia en el territorio y ser el referente ciudadano tradicional para la resolución de los problemas más comunes en la misma, no alcanza el grado de satisfacción esperado, siendo el 55,6\% la población satisfecha con su gestión. Si intentamos buscar una explicación a este nivel de insatisfacción, quizá la encontremos en que estos, los ayuntamientos, no intervienen de forma sustancial en la gestión de los ENP.

Cuando se pide nivel de satisfacción sobre «el gobierno regional», este tampoco sale bien parado, de tal modo que solo alcanza el 33,3\%. Si tenemos en cuenta que la calificación y la gestión administrativa de los espacios naturales protegidos son competencia de los gobiernos regionales, algo debe haber sucedido para encontrar ese gran rechazo. Quizá un exceso de celo por parte de la administración regional a la hora de controlar las iniciativas de desarrollo.

Para profundizar en el nivel de aceptación «del funcionamiento del sistema democrático» que ya alcanza los treinta y cuatro años de existencia, la consulta presenta un elevado nivel de indignación con un $77,8 \%$.

\subsection{El sentido de pertenencia}

Interrogados sobre su grado de identificación institucional, los entrevistados señalan la familia, o tal como se formula en la pregunta las «raíces familiares», el «pueblo», la «comarca», la «provincia»y «España» como las instituciones que despliegan el mayor poder identitario de adhesión, con el total de la población entrevistada identificada, arraigada y comprometida, seguidos de su sector profesional $(77,8 \%)$ y de la comunidad autónoma $(44,4 \%)$.

Si en el caso de «la familia», los lazos afectivos tienen gran solidez, cuando se plantea la identidad con «el pueblo», con el núcleo de población en el que se reside habitualmente e incluso en el que nacieron, el arraigo se pone de manifiesto con la misma fuerza. Aunque 
¿EN QUÉ MEDIDA ESTÁ USTED SATISFECHO CON...?

\begin{tabular}{|l|l|l|}
\hline & \multicolumn{2}{|c|}{$\%$} \\
\hline Su vida últimamente & $\begin{array}{l}\text { Parcial } \\
\mathbf{1 1 , 1}\end{array}$ & $\begin{array}{l}\text { Pleno } \\
\mathbf{8 8 , 9}\end{array}$ \\
\hline $\begin{array}{l}\text { La labor que realiza el órgano colegiado de } \\
\text { participación en el ENP }\end{array}$ & $\begin{array}{l}\text { Descontento } \\
\mathbf{0}\end{array}$ & $\begin{array}{l}\text { Contento } \\
\mathbf{1 0 0}\end{array}$ \\
\hline La labor de su ayuntamiento & $\begin{array}{l}\text { Insatisfecho } \\
\mathbf{4 4 , 4}\end{array}$ & $\begin{array}{l}\text { Satisfecho } \\
\mathbf{5 5 , 6}\end{array}$ \\
\hline La labor del gobierno regional & $\begin{array}{l}\text { Insatisfecho } \\
\mathbf{6 6 , 7}\end{array}$ & $\begin{array}{l}\text { Satisfecho } \\
\mathbf{3 3 , 3}\end{array}$ \\
\hline La situación económica de su región & $\begin{array}{l}\text { Resignado } \\
\mathbf{1 0 0}\end{array}$ & $\begin{array}{l}\text { Satisfecho } \\
\mathbf{0}\end{array}$ \\
\hline El funcionamiento de la democracia & Indignado & $\begin{array}{l}\text { Conforme } \\
\mathbf{2 2 , 2}\end{array}$ \\
\hline
\end{tabular}

Fuente: Elaboración propia.

el volumen de la muestra a veces nos haga dudar de la fuerza de la respuesta, creemos fuertemente asentados los vínculos territoriales de lo local, por próximo, inmediato y afectivo.

Cuando la escala disminuye y se alcanza «el ámbito comarcal», se muestra un total arraigo a la comarca. A este respecto hay que tener en cuenta que la mancomunidad de Cabañeros sólo actúa sobre cinco de los seis municipios del área de influencia socioeconómica del parque, mientras un sexto (Hontanar) pertenece a un grupo de acción local de la provincia de Toledo, de hecho el territorio del parque se integraría en una comarca histórica de mayores dimensiones, la comarca de Montes de Toledo, dividida entre las provincias de Ciudad Real y Toledo y fragmentada entre diversos grupos de acción local, lo que no ha contribuido precisamente a cohesionar su imagen ni de cara al exterior, con una marca territorial fácilmente identificable, ni de cara a sus propios residentes que se debaten entre distintas denominaciones e interlocutores institucionales.

Al continuar la encuesta con cuestiones referidas a una escala menor, como es «el marco provincial», las respuestas no cambian el resultado manifestado para el ámbito local, lo que nos podría indicar la solidez del concepto provincia arraigado en la población desde el primer tercio del siglo XIX, cuando Javier de Burgos diseñó el actual mapa provincial del estado español. Este concepto vincula fuertemente por formar parte de los datos básicos identitarios del individuo y estar plasmados en los documentos de identidad ciudadana (DNI y pasaporte).

Es en la consulta sobre los vínculos con «la comunidad autónoma», cuando se producen apreciables modificaciones en las respuestas, detectándose una escasa valoración, un nivel de desinterés del 44,4\%, hecho que coincide con la inexistente tradición regionalista del territorio en el momento de concretarse la nueva vertebración regional derivada de la constitución de 1978. Esta relación porcentual de respuesta, algo crítica, tiene parecido con la manifestada 
ante la pregunta sobre la satisfacción con el gobierno regional. En fin que los encuestados han manifestado cierta coherencia al responder, lo que nos permite mantener cierto estímulo de credibilidad en las respuestas obtenidas y en el caso que nos ocupa, algo de desprestigio sobre el concepto comunidad autónoma. El hecho de que la administración y gestión del parque nacional haya dependido exclusivamente de la administración central hasta 2006, de donde procedían y siguen procediendo importantes subvenciones, podría explicar la ambivalente relación de la población con la administración regional.

La escala territorial finaliza con una cuestión algo baladí a nuestro entender que es la de la vinculación al territorio llamado «España». La respuesta es la esperada, 100\% de vinculación total. Para finalizar se demanda de los encuestados su opinión sobre «el sector profesional» en el que ejercen su trabajo, algo que nos parece poco procedente ya que las profesiones de los representantes de las asociaciones deben ser muy diversas, por serlo la procedencia de los mismos, así como sus trabajos que poco tendrían que ver con ser integrantes de la comunidad que tutela la gestión de los ENP. La respuesta muestra un alto porcentaje de sentirse bien representado por sus sectores profesionales, el 77,8\%. Sería preciso conocer con más detalle la variedad de las profesiones, no de la formación, para buscar relaciones e incidencias de estas en los sentimientos de vínculos al territorio.

Igualmente, partiendo de su particular estatus de parque nacional, la categoría estrella de los espacios naturales protegidos, y del esfuerzo realizado en materia de desarrollo socioeconómico por la administración, puede entenderse la favorable valoración de los entrevistados $(77,8 \%)$ cuando se les pregunta si «la declaración del espacio ha permitido aumentar las ayudas a los habitantes de la zona» y crear nuevas oportunidades de desarrollo económico (cuadro 6). En cuanto a «la protección del medio natural», todos los entrevistados en el AIS coinciden en señalar que la declaración ha permitido mejorar sus posibilidades. A este respecto habría que recordar que el espacio se encuentra vallado y el acceso está limitado y controlado por el sistema de gestión de visitas del mismo. No ocurre lo mismo cuando se les pregunta si la declaración del espacio ha permitido «mejorar la conservación del patrimonio cultural», pregunta que contestan afirmativamente tan solo el 22,2\% de los entrevistados. Probablemente esta respuesta se deba al hecho de la escasez de bienes de interés cultural y/o conjuntos monumentales de cierta notoriedad, así como a la falta de apreciación de bienes inmateriales o del paisaje en su calidad de patrimonio cultural.

Cuando se trata de valorar si «la declaración de este espacio natural protegido ha permitido aumentar el uso recreativo/turístico de la zona», y que lleguen turistas, la valoración es muy positiva para la mayor parte de la población $(88,9 \%)$. Sin duda, lo reciente del desarrollo turístico del parque nacional, adaptado a las nuevas demandas del turismo rural explica esta situación. Progresivamente la tendencia generalizada de Cabañeros ha sido ir creciendo en visitas a pesar de las limitaciones y restricciones que el ENP sufre a la hora de canalizar los flujos (se trata del parque nacional con la relación más baja de visitantes por hectárea y año de toda la red española), uno de los principales motivos de conflicto entre la dirección del parque y los agentes implicados en el turismo rural en la zona (alojamientos, empresarios turísticos, etc.). Recientemente, a finales de 2009, el parque nacional de Cabañeros ha suscrito la Carta Europea de Turismo Sostenible (CETS), una iniciativa financiada por el Programa LIFE de la Unión Europea, que persigue avanzar de manera efectiva en los principios del turismo sostenible en espacios naturales protegidos. 
Para terminar este bloque de preguntas, cuando se interroga sobre si la declaración del espacio ha contribuido a «generar conflictos y problemas en la población residente», lo primero que habría que destacar es que la mayoría de las respuestas coinciden en señalar que eso no es así $(88,9 \%)$. No obstante, los desacuerdos entre los gestores del parque, los ayuntamientos y la asociación de afectados están presentes. La administración del parque apuesta por la visita controlada por itinerarios señalizados, incluyendo las visitas en todo terreno, a la vez que pretende conseguir una desestacionalización de la demanda de visitantes que se concentran mayoritariamente en otoño (berrea) y primavera, mientras que en verano e invierno los flujos descienden de forma significativa. En cambio, los ayuntamientos pretenden establecer más rutas en el parque y depositan en el turismo buena parte de las expectativas de desarrollo de la comarca, aspecto que apoyan directamente los empresarios turísticos, que además quieren que aumente el número de visitantes al ENP (Caro et al., 2009).

En relación a las iniciativas de desarrollo, las posturas son igualmente diversas. En opinión de la dirección del parque se han de apoyar las iniciativas de casas rurales, lo que supone una inclinación de la economía de la comarca hacia la terciarización como complemento de las rentas agrarias, mediante el soporte económico procedente de los ingresos del turismo rural en la zona. En cambio, la asociación de afectados (Aprofinca) apuesta por un mayor control de las ayudas. No obstante, todos los agentes creen que se trata de un apoyo fundamental para el desarrollo social y económico de la comarca.

Si analizamos la opinión en torno a la línea de subvenciones concedidas por el parque igualmente los puntos de vista son diversos. Para el propio parque se consideran fundamentales a la hora de orientar la economía de la zona, en cambio, ayuntamientos y empresarios turísticos afirman desconocer los criterios que utiliza la administración del parque para la concesión de las mismas y, de igual forma, Aprofinca sostiene que son ayudas muy dirigidas hacia las administraciones locales lo que dificulta su acceso a las mismas.

Finalmente, y respecto al tema de la conservación los gestores del parque defienden claramente su postura que apunta hacia la conservación de especies de flora y fauna así como la necesidad de investigar sobre las mismas y, en los casos en que haya habido alteraciones del ecosistema, se apuesta por su restauración ambiental. Ahora bien, esta postura conservacionista pura no es compartida por los ayuntamientos que consideran excesivas las restricciones y tachan la gestión de excesivamente burocrática incluso en la conservación, además de apostar por modelos de consenso y participación para la toma de decisiones relevantes y tocantes al parque. En este sentido, Aprofinca argumenta la idoneidad de indemnizaciones económicas como compensación a los propietarios que vean mermados sus actividades como consecuencia de las limitaciones de uso en las fincas.

Por último, los entrevistados muestran «confianza en el funcionamiento de las empresas de su territorio» así como en el futuro del mismo. La experiencia acumulada en la gestión de conflictos por parte de distintos equipos técnicos y de dirección, así como el apoyo de la administración en forma de subvenciones e inversiones directas justifica que, a pesar de tratarse de un territorio rural desfavorecido, aquejado por problemas de despoblación y envejecimiento, sus habitantes tengan una percepción más favorable del funcionamiento del órgano colegiado así como de las expectativas abiertas por los recientes desarrollos de turismo rural de los que se ha beneficiado la comarca. 


\begin{tabular}{|l|l|l|}
\hline & \multicolumn{2}{|c|}{$\%$} \\
\hline Aumentar las ayudas a los habitantes de la zona & $\begin{array}{l}\text { Desconocedor } \\
\mathbf{2 2 , 2}\end{array}$ & $\begin{array}{l}\text { Conocedor } \\
\mathbf{7 7 , 8}\end{array}$ \\
\hline Crear nuevas oportunidades de desarrollo económico & $\begin{array}{l}\text { Inoperativo } \\
\mathbf{0}\end{array}$ & $\begin{array}{l}\text { Operativo } \\
\mathbf{1 0 0}\end{array}$ \\
\hline Proteger el medio natural & $\begin{array}{l}\text { Desfavorable } \\
\mathbf{0}\end{array}$ & $\begin{array}{l}\text { Favorable } \\
\mathbf{1 0 0}\end{array}$ \\
\hline Conservar el patrimonio cultural & $\begin{array}{l}\text { Negativo } \\
\mathbf{7 7 , 8}\end{array}$ & $\begin{array}{l}\text { Positivo } \\
\mathbf{2 2 , 2}\end{array}$ \\
\hline $\begin{array}{l}\text { Aumentar el uso recreativo de la zona, y que lleguen } \\
\text { turistas }\end{array}$ & $\begin{array}{l}\text { Impermeable } \\
\mathbf{1 1 , 1}\end{array}$ & $\begin{array}{l}\text { Permeable } \\
\mathbf{8 8 , 9}\end{array}$ \\
\hline $\begin{array}{l}\text { Generar conflictos y problemas en la población } \\
\text { residente }\end{array}$ & $\begin{array}{l}\text { Conflictivo } \\
\mathbf{1 1 , 1}\end{array}$ & $\begin{array}{l}\text { Cordial } \\
\mathbf{8 8 , 9}\end{array}$ \\
\hline
\end{tabular}

Fuente: Elaboración propia.

\subsection{Las redes sociales}

De acuerdo con la mayor parte de los especialistas, no hay duda de que la participación en las actividades sociales, o lo que es lo mismo, la «pertenencia o inclusión en redes», es central para el bienestar social. En cualquier caso, la literatura al respecto no es concluyente acerca de las relaciones entre vida asociativa y desarrollo económico. El número de asociaciones existentes en un territorio parece ser relativamente irrelevante; lo que importa es la intensidad de las relaciones y actividades que mantienen vinculados a los individuos.

De las respuestas recogidas acerca de la pertenencia a asociaciones horizontales se desprende, en primer lugar, la baja tasa de asociacionismo que rara vez supera la respuesta de una o ninguna para las distintas categorías de asociaciones. En general prevalece la desmotivación y la desvinculación, si bien aquí se hace notar la diferencia entre los miembros de los órganos colegiados y los de las propias asociaciones. El grado de «politización» de los primeros explicaría justamente su mayor tasa de vinculación. Para el órgano colegiado, destaca la categoría de «ONG's», mientras para los miembros de asociaciones entrevistados la categoría dominante es la de «asociaciones juveniles, de jubilados o de mujeres», seguidas por «asociaciones culturales». Por último, las redes de carácter vertical, como «asociaciones profesionales», «empresariales o agrícolas» y «colegios profesionales» son irrelevantes.

En cuanto a las actividades realizadas para transformar su espacio, la totalidad de los entrevistados reconoce su colaboración con alguna organización o asociación (no política); y algo más de la mitad de los entrevistados manifiestan que se han puesto en contacto con un político/autoridad/funcionario $(55,6 \%)$. Pero, en general, prevalece aquella población que se muestra desinteresada en las acciones expuestas por el encuestador. 
La población presenta cierta desidia a la hora de pasar a la acción e intentar poner remedio a problemas existentes en su entorno o que las cosas funcionen mejor en su espacio natural. Esta situación se hace extrema -con un $100 \%$ de población desinteresada- en los casos de la participación en actividades ilegales de protesta, en el caso de la firma en una campaña de recogida de firmas y en la participación en manifestaciones autorizadas.

Para terminar, las redes de carácter vertical, asociaciones profesionales, empresariales o agrícolas y colegios de carácter profesional, tienen cierta relevancia, especialmente el tejido asociativo, mientras el peso de la pertenencia a colegios profesionales es irrelevante.

\section{CONCLUSIONES}

Como ya apuntábamos en párrafos precedentes, las relaciones causa-efecto entre capital social y desarrollo distan mucho de estar claras. La existencia de un rico capital social no es el único «pre-requisito» para el desarrollo, pero tendría la capacidad dual de ser un recurso que podría movilizar otros recursos (capital económico, político y cultural) para generar o ampliar los «beneficios» económicos, culturales, políticos y sociales siempre en relación dialéctica. Algunos autores argumentan que los recientes y profundos cambios económicos y políticos favorecidos por las multinacionales y los gobiernos han afectado las actitudes de los ciudadanos hacia sus gobiernos y la sociedad en su conjunto (Portes y Landolt, 1996). Sin embargo, es posible que la acción gubernamental no sólo pueda conducir a un declive del capital social sino también a su incremento, este es precisamente el objetivo de los programas de desarrollo rural que han emanado tanto de la Unión Europea como de la administración central.

Centrándonos en nuestro estudio de caso, el parque nacional de Cabañeros, en el marco de la confianza estratégica y en relación con la confianza en el futuro de su comarca, los individuos entrevistados y encuestados se muestran optimistas y esta confianza se debe a la creencia de que sus acciones pueden influir en el medioambiente, y que las empresas de su territorio son viables en un elevado porcentaje.

Por lo que respecta a la confianza normativa, la población se presenta como fundamentalmente íntegra y educada. La confianza en colectivos e instituciones presenta una clara incondicionalidad respecto a instituciones como la familia o la policía, presentando una cierta desconfianza cuando se trata de otras instituciones que forman el elenco administrativo del ámbito territorial, desconfianza o descrédito que aumenta en orden centrífugo, es decir, el ayuntamiento, la mancomunidad, la diputación y el gobierno regional. No obstante, la U.E. queda bien considerada con niveles de confianza altos quizá por el conocimiento de que los programas de desarrollo llevan financiación de los fondos comunitarios. Sobre la gestión, existen elevadas tasas de satisfacción; hay un elevado porcentaje de población que opina que los órganos de gestión del parque son eficientes, accesibles y operativos.

En materia de confianza cognitiva, la labor que realiza el órgano colegiado del parque nacional resulta muy valorada por la población de Cabañeros, tanto por los miembros del propio patronato como por las asociaciones, sin embargo los ayuntamientos de la zona no alcanzan el grado de satisfacción esperado respecto a su gestión, aunque peor parado sale el gobierno regional, quizá por el control que este hace de las iniciativas de desarrollo en la zona. 
Si nos centramos en el sentido de pertenencia, observamos fuertes vínculos familiares y territoriales de lo local y de España frente a los regionales, hecho que puede explicarse por la falta de tradición regional en Castilla-La Mancha. Son las raíces familiares, la comarca, la provincia y España las instituciones que despliegan el mayor poder identitario de adhesión.

Por lo que se refiere a los efectos producidos por el ENP, la mayoría de la población encuestada cree que la declaración del espacio ha permitido aumentar las ayudas a los habitantes de la zona, mejorar sus posibilidades, aumentar el uso recreativo y potenciar el desarrollo turístico del parque nacional. La declaración primero de Parque Natural y posteriormente de Parque Nacional ha supuesto, sin duda, una apertura social del territorio, que ha pasado de ser conocido por el debate en torno a su posible militarización a ser un espacio natural de reconocida notoriedad, destacando los valores naturales y paisajísticos que conservaba el ecosistema. Así pues, la declaración ha tenido sin duda aspectos positivos, aunque también sus sombras.

Entre los primeros, el «descubrimiento social» de esta comarca y la adquisición de una identidad propia. A los beneficios para el territorio se suman las iniciativas procedentes de fondos europeos, que están favoreciendo un cambio económico progresivo hacia una cierta terciarización con predominio de las actividades vinculadas al turismo y al medio ambiente. Todo ello ha supuesto, junto con las subvenciones procedentes del Organismo Autónomo de Parques Nacionales, una mejora importante en la calidad de vida de la población.

No obstante, todos los municipios del AIS han venido perdiendo efectivos demográficos de manera constante con el consiguiente envejecimiento de la población y la falta de reemplazo generacional, proceso relacionado con la carencia de servicios sanitarios especializados y sobre todo la falta de expectativas laborales.

Los ayuntamientos y los empresarios turísticos siguen preocupados por los problemas de gestión del uso público y de los aprovechamientos en la zona, y depositan en el turismo buena parte de las expectativas de desarrollo de la comarca. La administración del parque apuesta por la visita controlada y la desestacionalización. En cualquier caso, los permanentes desencuentros existentes sobre el uso y gestión del parque nacional se han traducido en hechos como que el PORN se encuentre anulado por sentencia del Tribunal Constitucional mientras el PRUG, tras una década de tramitación, continúe sin aprobarse.

En relación con las redes sociales, existe una baja tasa de asociacionismo y diferentes comportamientos entre los miembros de los órganos colegiados y los de las asociaciones. El grado de politización de los primeros explicaría su mayor tasa de vinculación, destacando la categoría de ONG`s, mientras para los miembros de asociaciones la categoría dominante es la de asociaciones juveniles, de jubilados o de mujeres, y culturales. La población presenta cierta desidia a la hora de pasar a la acción e intentar poner remedio a los problemas de su comarca.

Todo lo expuesto hasta aquí nos mueve a afirmar que la confianza en la acción colectiva depende del papel desempeñado por el Estado en términos de respuestas a las necesidades individuales y colectivas. La principal función del Estado a escala local es suministrar servicios públicos, y la falta de servicios públicos genera una comunidad que no confía en la acción colectiva; y, por consiguiente, la voluntad de construir capital social aparece como muy débil. En consecuencia, cuando una comunidad es pobre en capital social, el Estado/la administración pública, debe proporcionar un mejor nivel de infraestructuras/equipamientos/ servicios públicos, a fin de crear un clima de confianza en la acción colectiva. 


\section{BIBLIOGRAFÍA}

BOURDIEU, P. (2001): «El capital social. Apuntes provisionales». Zona Abierta, 94/95, 83-87.

BRYDEN, J.M. (1998), «Development strategies for remote rural regions: What do we know so far?, en Paper presented at the OECD International Conference on Remote Rural Areas: Developing through Natural and Cultural Assets», Albarracín, Spain, November 5-6.

BUCIEGA, A. (2004): «El potencial del capital social para el desarrollo de las zonas rurales», en XXX Reunión de Estudios Regionales. La política regional en la encrucijada. Disponible en http://www.aecr.org/web/congresos/2004/pdf/167.pdf

CASTROVIEJO, M. (1993): «Planificación y gestión de los parques nacionales en España». El Campo, n'. 128, 15-42.

CHIMI, C.J. y RUSSELL, D.R. (2009): The Likert Scale: A Proposal for Improvement Using Quasi-Continuous Variables. Washington DC, Proc ISECON, v 26.

CORRALIZA, J.A. (2010): Imagen social de los espacios naturales protegidos: implicación social y resistencias. Madrid. Universidad Autónoma.

CORRALIZA, J.A., MARTÍN, R., BERENGUER, J. y MORENO, M. (2002): «Los espacios naturales protegidos, escenarios de intervención psicosocial». P sychosocial Intervention. Madrid. Colegio Oficial de Psicólogos. vol. 11, 3, 303-316.

ESPARCIA. J., BUCIEGA, A.J. y NOGUERA, J. (2002): «Las agrupaciones Locales de Desarrollo Rural como instrumentos de desarrollo, cambio y nueva gobernabilidad en los territorios rurales». Cooperativismo y Economía Social. Universidad de Vigo, Servicio de Publicaciones, $\mathrm{n}^{\circ}$. 24, 59-76.

EUROPEAN COMMISSION. Image 2000 \& Corine Land Cover 2000 Project. Disponible en http://image2000.jrc.ec.europa.eu/

FERNÁNDEZ, T.R. (1975): «Parques nacionales y protección de la naturaleza». Cívitas. Revista Española de Derecho Administrativo, 5, 215-223.

FORONDA, C. y GALINDO, L. (2010): «La dimensión del capital social en el patrimonio rural» en Territorio, paisaje y patrimonio rural (Leco, F. et al, Coord.). Cáceres. Universidad de Extremadura, Servicio de Publicaciones, 489-499.

GARAYO, J.M. (1998): «La participación de la población local en el proceso de declaración y planificación de los espacios naturales protegidos: el parque natural de Valderejo (19921995)». Inguruak, $\mathrm{n}^{\circ}$. 21, 227-252.

GARCÍA, J.L., JIMÉNEZ, J. y MUÑOZ, J. (1996): «El Parque Nacional de Cabañeros: un área representativa de los paisajes del monte mediterráneo del centro de España». Boletín de la Real Sociedad Geográfica, nº 32, 181-218.

HERNÁNDEZ, R., FERNÁNDEZ, C. y BAPTISTA, P. (2003): Metodología de la investigación. México, DF: McGraw Hill.

HERREROS, F. (2004): The Problem of Forming Social Capital: Why trust?, Nueva York. Palgrave.

INSTITUTO NACIONAL DE ESTADÍSTICA. Disponible en http://www.ine.es/

JOHANNISSON, B. (1995): «Paradigms and entrepreneurial networks -some methodological challenges». Entrepreneuship and Regional Development, $\mathrm{n}^{\circ}$ 7, 215-231. 
JUNTA DE COMUNIDADES DE CASTILLA Y LEÓN. Disponible en http://www.jcyl.es web/jcyl/MedioAmbiente/es/Plantilla100/1131977535996/_/_

LÓPEZ, E.K.; JUÁREZ, F. (2004): Apuntes de Estadística Descriptiva (Notes on Descriptive Statistics). México DF, Instituto Nacional de Psiquiatría Ramón de la Fuente.

MAGNANI, N. y STRUFFI, L. (2009): «Translation sociology and social capital in rural development initiatives. A case study from the Italian Alps». Journal of Rural Studies, $\mathrm{n}^{\circ}$ 25, 231-238.

MAILLAT, D. (1995): «Territorial dynamic, innovativemilieus and regional policy». Entrepreneurship \&Regional Development, $\mathrm{n}^{\circ}$ 7, 157-165.

NORTH, D.C. (1986): «The new institutional economics». Journal of Institutional and Theoretical Economics, $\mathrm{n}^{\circ} 142$ (2): 230-237.

OSTI, G. (2000): «LEADER and partnerships: the case of Italy», Sociología Ruralis, n 40 (2), 172-180.

PORTES, A. y LANDOLT, P. (1996): «The Downside of Social Capital», The American Prospect, $\mathrm{n}^{\circ}$ 26, 18-21.

RADALIFFE, S.A. (2004): «Geography of development: development, civil society and inequality ¿social capital is (almost) dead?», Progress in human geography, vol. $28, \mathrm{n}^{\circ}$ 4, 517-527.

SCOTT, A. (1998): Regions and the World Economy. Oxford, Oxford University Press.

SERRANO, Ó. (2008): «Efectos de la declaración de un espacio natural protegido en territorios de ruralidad profunda», Scripta Nova. vol. XII, núm. 270 (85). Universidad de Barcelona. Disponible en $\langle$ http://www.ub.es/geocrit/sn/sn-270/sn-270-85. htm

SHUCKSIMITH, M. (2000): Endogenous Development, Social Capital and Social Inclusion: Perspectives from LEADER en the UK. Sociologia Ruralis $\mathrm{n}^{\circ} 40$ (2), 208-218.

STÖHR, W.B. (1981): Development from below: the bottom-up and periphery inward development paradigm, en Development from Above or Below? (Stöhr, W.B.; Taylor, D.R. eds.) Chichester, J. Wiley and Sons

TROITIÑO, M.A. et al. (2006): «El Parque Nacional de Cabañeros: encuentros y desencuentros en la gestión de un territorio de ruralidad profunda», en Gobernanza territorial en España (Romero, J. y Farinós, J. eds), Universitat de València, 245-270.

VALENZUELA, M. (1989): «Inventario y descripción actual de espacios naturales en España y en Francia», en Supervivencia de los espacios naturales (Fourneau, F. Dir.). Madrid. MAPA. 365-373.

WIESINGER, G. (2007): «L'importance du capital social dans le développement rural, les réseaux et les prises de décision dans les zones rurales ». Revue de Géographie Alpine, vol. $95, n^{\circ} 4,29-42$. 
